\title{
Yaşlılarda Polifarmasi ve Akıleı İlaç Kullanımına Aile Hekimliği Yaklaşımı
}

\author{
Nurten ELKIN ${ }^{*}$
}

\section{Öz}

Yaşlılık büyüme ve gelişmenin devam ettiği bir ileri yaşam sürecidir. Yaşlılık ve yaşlanma tüm dünya ve ülkemiz için gittikçe önemi artan bir demografik olgudur. Bu nedenle sağllk sorunları önem kazanmaktadır. Yaşlanma ile birlikte organ fonksiyonları azalırken, kronik hastalık sayısında artış olmaktadır. Dolayısıyla bu durum çoklu ilaç kullanımını da beraberinde getirmektedir. Aynı anda en az dört ilacın kullanımı olarak tanımlanan polifarmasi, yaşlının yaşam kalitesini artırmayı hedefleyen geriatrik ve gerontolojik yönetimde güncel çalışma alanlarından birisidir. Yaşlıdaki ilaç tedavisinin de temel amacı, yaşlının akut ve kronik hastalıklarının tedavisi, bağımlılıklarının önlenmesi ya da en aza indirgenmesi ve yaşam kalitesinin maksimum düzeye çıkarılmasıdır. Bu nedenle yaşlı hastaya kullandığı her ilaç tıbbi açıdan gerekli olduğu takdirde ilaç sayısında kısıtlamaya gidilmeksizin tedavi planı uygulanabilir. Zorunlu ilaçların reçete edilmesi ve kullanılması dışında akılcı ilaç kullanımı yaklaşımı benimsenmelidir. Akılcı ilaç kullanımı; bireylerin klinik bulgularına ve bireysel özelliklerine göre uygun ilacı, uygun süre ve dozda en düşük maliyetle ve basit bir kullanım yoluyla kullanabilmelerini sağlamaktır. Çalışmanın amacı; özellikle birinci basamak sağlık hizmetlerinin sunulduğu Aile Sağlığı Merkezlerinde çalışan aile hekimleri ve aile sağlığı elemanlarının; hizmet verdikleri kayıtlı yaşlı nüfusun geriatrik değerlendirmelerini periyodik olarak yapmaları ve bu değerlendirme kapsamında hastanın kronik hastalıkları belirlenerek ve kayıt altına alınarak yaşlıların kullanmaları gereken ilaç tedavilerinde akılcı ilaç kullanım prensiplerine göre hastaya, yakınına ya da bakım veren kişi ya da kuruma gerekli bilgilendirme ve danışmanlıkların yapılması konusunda farkındalık oluşturmaktır.

Derleme Makale (Review Article)

Geliş / Received: 21.11.2019 \& Kabul / Accepted: 13.05.2020

DOI: https://doi.org/10.38079/igusabder.649423

${ }^{*}$ Dr. Öğr. Üyesi, İstanbul Gelişim Üniversitesi Sağlık Bilimleri Yüksekokulu, Gerontoloji

Bölümü, İstanbul, Türkiye, nelkin@gelisim.edu.tr ORCID http://orcid.org/o000-0002-9470$\underline{2702}$ 
Anahtar kelimeler: Polifarmasi, yaşlı, akılcı ilaç kullanımı.

\title{
Family Medicine Approach to Polypharmacy and Rational Drug Use in the Older People
}

\begin{abstract}
Old age is an advanced stage of growth and development. Aging and old age are an increasingly important health problem for the world and our country. With aging, organ functions decrease and the number of chronic diseases increases. Therefore, this situation brings with it the use of multiple drugs. Polypharmacy, a term defined as the use of at least four drugs at the same time, is an important issue in geriatric management which aims to improve the quality of life of the older people. The main purpose of drug treatment in the older people; treatment of acute and chronic diseases of older people, prevention or minimization of addictions and maximizing quality of life. Therefore, if it is required medically, the patient should take the required number of drug treatments; but it must be noted that rational use of drugs is appropriate. Rational drug use; according to the clinical findings and the characteristics of individuals to provide the appropriate drug, appropriate time and dose at the lowest price and with the easiest way. Our main goal in the older individual is not to reduce or cut the number of drugs used; appropriate drug or drug group, with appropriate way, appropriate time, with well informed by professionals and follow-up to use. The aim of this study; raising awareness of especially family physicians and family health personnel working in Family Health Centers where primary health care services are provided; in the geriatric evaluations of the older population they serve, periodically and within the scope of this evaluation, the patient should be identified and recorded with their chronic diseases and used in drug treatments; also raise awareness about the necessary information and counseling to the patient, relative or caregiver or institution according to rational drug use principles.
\end{abstract}

Keywords: Polypharmacy, older people, rational drug use.

\section{Giriş}

Yaşlanmaya bağlı organ rezervlerinde azalma ve fizyolojik olarak çoğu organda işlevsel bir gerileme görülmektedir. Bu işlevsel gerileme hızı ve düzeyi bireyler arasında ve aynı bireydeki organlar arasında değişkenlik gösterebilmektedir ${ }^{1}$. Yaşlanmaya bağlı gelişen bu fizyolojik ve patolojik değişiklikler bireylerin, çoğunlukla birden fazla hastalık, hastalık ve tedavi komplikasyonları ile karşı karşıya kalmalarına neden olmaktadır. Dolayısıyla yaşlı bireydeki bu çoklu hastalık varlığı; polifarmasi uygulamalarını 
kaçınılmaz hale getirmektedir ${ }^{2}$. Polifarmasi, literatürde çoklu veya aşırı ilaç tüketimi olarak tanımlanmıştır3. Yaşlılardaki çoklu ilaç kullanımı, doğru tedavi yaklaşımları uygulandığında, yan etkileri takip edilerek kontrol altına alındığında çoklu hastalıkların (komorbidite) tedavisinde son derece etkilidir. Fakat bununla birlikte polifarmasi yaşam kalitesinin düşmesine, sağlık harcamalarının artmasına, hasta uyumunda azalmaya ve hatta ölümlere de neden olabilmektedir ${ }^{4,5}$. Yaşlı bireyler ilaçlara bağlı yan etkiler konusunda daha hassas ve savunmasızdır ${ }^{4}$. Bu makalede yaşlılık döneminde polifarmasi ve akılcı ilaç kullanımına yönelik sağlık hizmetlerinde sunulabilecek önerilere yer verilecektir.

\section{Yaşlılık Döneminde Polifarmasi}

Polifarmasi bir günde dörtten fazla ilacın kullanılması ile tanımlanan bir durum olmakla birlikte tedavi planında ilacın sayısından ziyade tedavi rejimine ve hedefe odaklanmak reçete yönetiminin temel ilkesidir. Buna karşın polifarmasi geriatrik bir sendrom olarak görülmekte olup ileri yaş ile birlikte artmakta ve ülkeler arasında da değişkenlik göstermektedir. Özellikle 75 yaşın üzerindeki yaşlılarda bu oranın yaklaşı \%35-40 civarında olduğu bilinmektedir 5 . Yaşlllarda mevcut ilaç rejiminin öngörülmeyen bir etkisini telafi etmek için yeni bir ilacın yazılması ve tedaviye eklenmesi olağandışı bir durum olmayıp buna "reçete kaskadı" denilmektedir.

Polifarmasinin nedenleri değerlendirildiğinde karmaşık ve çok yönlü bir tablo ile karşılaşılmaktadır6-8:

\section{Polifarmasinin Nedenleri}

\section{Hasta İle İlişkili Nedenler}

- Bilişsel sorunlar

- Fonksiyonel yetersizlik

- Yeti kayıları

- Eğitim düzeyi

- Reçetesiz ilaç kullanımı

- Bitkisel tedavilerin hekime haber vermeden ve bilinçsiz kullanımı 
- Yaşlının birden çok hekime gitmesi

\section{Bakımveren ve Aile Üyeleri İle İlişkili Faktörler}

- Yaşlı için çok sayıda ilaç reçete edilmesinin onun sağlığı ile daha yakından ilgilenmek anlamına geldiği algısı,

- Farklı semptomlar için yaşlıya çok sayıda farklı ilaç vermek,

- Bakım verilen yaşlı için komşu, arkadaş ve yakınlarının önerisi ile ilaç kullanma eğilimi,

- Önceden reçete edilmiş ilaçların yaşlı birey ya da yakını tarafından tekrar reçete edilmesinin istenilmesi,

- Tedbir olarak çok sayıda ilacın reçete ettirilerek evde depolanması ve dolayısıyla hekim önerisi olmadan kullanılmasıdır.

\section{Sağlık Profesyonelleri İle İlişkili Faktörler}

- Yaşlının öyküsünün alınması sırasında eksik bilgiler bulunması

- Reçete kaskadı ve semptomatik tedavi için hayati öneme sahip olmayan ve bırakılacak çok sayıda ilaç reçete edilmesi

- Geriatrik sendrom tablolarının net ve açık bir şekilde okunamaması

- İyatrojenik tablolar

- Medula sistemi ve reçeteleme düzeneklerinin entegre hale getirilememesi

\section{Tedaviye Uyum ve Polifarmasi}

Yaşlı bireylerde ilaç uyumunu etkileyen birçok unsur olup bunların bilinmesi ve yaşlıya ya da bakım verene gerekli bilgilendirme ve danışmanlığın verilmesi son derece önemlidir. Yaş, cinsiyet, eğitim durumu, medeni durum, ırk, kültürel özellikler, inançlar ve değerler, yalnız yaşama, sosyal destek gibi sosyal özellikler, görme ve işitme gibi duyularda meydana gelen değişiklikler, kronik hastalıkların sayısı, komorbidite, çok sayıda ilaç kullanımı, ilaç yan etkilerinin olacağı kaygısı, depresyon ve stres gibi öz bakımını yerine getirmesini engelleyici durumlar tedaviye uyumu etkileyen etmenlerdir. Çok sayıda kronik hastalığı olan, birden fazla sağlık kurumuna başvuran, çok sayıda ilaç reçete edilen, karmaşık tedavi planı uygulanan hastalarda ve alkol alışkanlığı olan yaşlı 
bireylerin tedaviye uyumları daha güç olmaktadır. Kullandığı ilaç bilgisine sahip olmayan, sosyal güvencesi olmayan, yalnız yaşayan sosyal desteği olmayan bireylerde de tedaviye uyum zor olabilmektedir. Bunun dışında hastayı takip eden tek bir hekimin olmaması, hasta hekim iletişiminde yaşanan zorluklar ve evde bakım hizmetlerinin kurumsallaşmasındaki yetersizlikler gibi durumlarda yine tedaviye uyumu zorlaştırmaktadır. İlaç prospektüslerini inceleyerek aşırı kaygı nedeniyle tedaviyi terk etme ya da yarım bırakma da olabilecek sorunlardandır9-12.

İlaç tedavisine uyumu artırmak ve güvenli kullanımı sağlayabilmek için bazı risk etmenlerinin bilinmesi önemlidir. Örneğin, yaşlı bireyin ilaç dozunu almayı unuttuğunda ne yaptığı, kullandığı ilaçların yan etkilerini bilip bilmediği, hangi yan etkilerde sağlık kurumuna başvurabileceği, önerilen ilaçların kullanım amacını ve ilaç kullanım süresini bilip bilmediği, bu ilaçları daha önceden kullanıp kullanmadı̆̆ı, ilaç kullanımını hatırlatıcı not, alarm veya ilaç kutusu gibi yardımcılardan yararlanıp yararlanmadığı sorulmalıdır. Aynı şekilde, sosyal güvence durumu, ilaçları bütçesinden karşılıyorsa maddi sıkıntı yaşayıp yaşamadığı ve son olarak da ilaç tedavisinden sonra kendini daha iyi hissedip hissetmediği ve tedaviye cevabı sorulmalıdır9,12.

Ülkemizde hekim kontrolü olmadan ve reçetesiz ilaç kullanımı sık görülen bir durumdur. Ülkemizde yapılan bir çalışmada yaşlıların ilaç almalarında \%52,6'sının hekim, \%21,1'inin kendi isteği, \%13,2'sinin arkadaş, \%7,9'unun eczacı, \%5,2'sinin komşu önerisi olduğunu bulmuşlardır ${ }^{13}$. Bu şekilde alınan ve ilaç dışı olarak adlandırılan takviyeler mevcut ilaçlarla etkileşime girebilir ve basit bir alerjiden ölüme kadar birçok ağır komplikasyona neden olabilirler. $\mathrm{Bu}$ nedenle, hastaya ilaç dışı olarak adlandırılan takviyeleri kullanıp kullanmadığının sorgulanması önemlidir ${ }^{14}$. İlaç tedavisine yanıtta bireyin kronolojik yaşından çok fizyolojik yaşı önemlidir. Fizyolojik değişikliklerin şiddetine göre ilaç tedavisine yanıt ve riskler de değişebilmektedir. Yaşlılıkta görülen bu fizyolojik değişiklikler ilaç farmakokinetiğini ve farmakodinamiğini etkilemektedir.

Yaşlı bireylerde; mide asit sekresyonunda, mide sıvısı miktarında, mide kan akımında, mide-bağırsak motilitesinde, mide boşaltım hızında, tükürük salgısında, kan alımında, deri turgorunda azalma, yağ dokusunda ile derideki keratinize hücrelerdeki artma ilaçların farmakokinetiğini etkiler. Farmakodinamik açıdan ise hedef organlarda meydana gelen patolojik değişiklikler ilaçlara verilen yanıtı etkiler. Organlardaki reseptörlerin ilaçlara daha duyarlı ya da duyarsız olmasına bağlı olarak reseptörler bazı 
ilaçlara normal yanıt verirken bazılarına verdikleri yanıt azalabilir. Bu durum yaşlı bireylerin ilaçlardan yararlanışı ya da toksikasyon riskini artırabilir. Bu değişimlere ek olarak ilaç reaksiyonları, besin ilaç etkileşimleri gibi tablolar da yaşlılar için akılcı ilaç kullanımı ve onlarla ilk elden temasta bulunan birincil basamak hekimlerin bu konuya özen göstermelerini önemli bir konu haline getirmektedir ${ }^{15}$.

İlaç reaksiyonu; ilaç-ilaç ve ilaç-hastalık etkileşimi olarak iki şekilde görülür. İlaç-ilaç etkileşimi bir ilacın başka bir ilaçla birlikte kullanıldığında ortaya çıkan reaksiyonudur. Kullanılan ilaç sayısı, deneyimlenmiş ilaç reaksiyon öyküsü, 4 ve üzerindeki komorbit durum, karaciğer hastalığı, kalp yetersizliği, böbrek hastalığı, bilişsel bozukluk, yalnız yaşama, tedaviye uyumsuzluk öyküsü, tanılanmış psikiyatrik bozukluk, madde kötüye kullanım öyküsü ve antikoagülanlar ile insülinler gibi yüksek riskli ilaçların kullanımı durumları yaşlıda ilaç reaksiyonu riskine neden olan etmenler olarak sayılabilmektedir9,15. İlaç-hastalık etkileşimi ise bazı ilaçların bazı hastalık varlığında kullanıldıklarında yol açtıkları olumsuz etkilerdir. Örneğin; nonsteroid anti inflamatuar ilaçların hipertansiyon hastalarında kullanımında; kan basıncı artışına, peptik ülser vakalarında kullanıldıklarında; gastrointestinal kanamalara neden olabilecekleri gibi ${ }^{16}$. İlaç- besin etkileşimi; ilaç-besin etkileşimleri yaşlı bireylerde ciddi hastalık ve ölüm nedenleri arasında sayılmaktadır. Bazı besinlerin kullanımı ya da yetersizliği ilaçların biyoyararlanımını artırarak ya da azaltarak istenmeyen etkilere neden olmaktadır ${ }^{9,15}$.

\section{Yaşlılarda Akılcı İlaç Kullanımı}

Yaşlılarda çoklu ilaç kullanımına yol açan problemler sonucunda önleyici bir yaklaşım olarak akılcı ilaç kullanımına duyulan bir ihtiyaç ortaya çıkmıştır. Yaşlılarda akılcı ilaç kullanıminda uygulanan tedavi rejimi endikasyon, uygunluk, minimum etkin doz, zamanlama, etkinlik, yan etkiler, toksisite ve ilaç-ilaç etkileşimi açısından ayrı ayrı değerlendirilmeli ve bu işlem periyodik olarak yapılmalıdır ${ }^{16}$. Dünya Sağlık Örgütü’nün (DSÖ) tanımına göre; akılcı ilaç kullanımı; "bireylerin klinik bulgularına ve bireysel özelliklerine göre uygun ilacı, uygun süre ve dozda en düşük fiyata ve kolayca sağlayabilmeleridir”. Akılcı ilaç kullanımı, hastaya doğru tanının konmasını, tedavi seçenekleri arasından etkinliği kanıtlanmış ve güvenilir tedavinin seçilmesini, hastaya açık, net ve anlaşılır bilgiler vererek tedaviye başlanması ve tedavinin sonuçlarının 
izlenmesi ve değerlendirilmesini içermektedir. Yaşlılarda akılcı ilaç kullanımına ilişkin önerileri şu şekilde özetlenebilir:

- Yaşlı bireyde tedavi doğru tanıya dayanmalı, ilaç tedavisinin gerekli olup olmadığı, sigara ve alkol alışkanlığı değerlendirilmeli, önerilen ilaçların farmakolojik özellikleri bilinerek, birden çok ilaç kullanılacaksa birbirleri ile etkileşimleri bilinmeli, ilaç tedavisinde uygun hasta, uygun ilaç, uygun doz, uygun veriliş yolu, uygun etki/yanıt, uygun zaman ve doğru kayıt ilkelerine uyulmalıdır.

- Tedaviye mümkün olduğunca düşük doz ile başlanarak yavaş yavaş artırılmalı ve yaşlının uyumunu kolaylaştırmak için tedavi planı olabildiğince basit olmalıdır.

- Yaşlı birey ve bakım veren kişi ilaç tedavisinin amacı, gerekliliği ve olası yan etkileri konularında eğitilmeli, yutma güçlüğü olan yaşlılarda aspirasyon riskini önlemek için tablet formundan ziyade toz şeklinde ya da ağız yoluyla alınacak ilaçların bol suyla oturur pozisyonda almaları sağlanmalıdır.

- Yaşlıda doku elastikiyetinin azalması doku zedelenmesine neden olabileceğinden intramüsküler ve subkutan enjeksiyon uygulamalarından mümkün olduğunca kaçınılmalıdır8-10.

\section{Yaşlılık Döneminde Kimi Riskli İlaç Grupları ve Akılcı İlaç Kullanımı}

Sağlık Bakanlığı'nın yaşlılar üzerinde yaptığı bir araştırmaya göre, ülkemizdeki 65 yaş üzerindeki yaşllların; \%9o’ında genellikle bir, \%35’inde iki, \%23’ünde üç ve \%14’ünde dört veya daha fazla kronik hastalığın bir arada bulunduğu belirtilmektedir ${ }^{14}$. Söz konusu kronik hastalıklar nedeniyle risk arz eden kimi ilaç gruplarından bazılarına yönelik öneriler siralanacaktır:

Antikolinerjik ve Sedatif İlaçların Akılcı Kullanımı: Antikolinerjik ve yatıştırıcı ilaçların uzun süreli kullanımı, kötüleşen biliş ve fiziksel işlev düşüşü ile ilişkilidir. İlaç azaltma (deprescribing), yaşlı kişilerde çeşitli sağlık sonuçlarını potansiyel olarak iyileştirirken, çoklu ilaçları en aza indirmeye yardımcı olabilecek önerilen bir müdahaledir ${ }^{16}$. Yaşlılara antikolinerjik ve yatıştırıcı ilaçlar reçete edilirken hekimin kar-zarar dengesini gözetmesi, ilaç dozları ve etkilerini yakından izlemesi gerekir. 
Ağrı Kesici İlaçların Akılcı Kullanımı: Steroid olmayan antienflamatuar ilaçlar (NSAID'ler), analjezik, antienflamatuar ve antipiretik etkilere sahiptir, ancak antiplatelet aktiviteye sahip değildir, kanama süresini etkilemez ve gastrointestinal (GI) sistem için toksik değildir. NSAID'ler, hafif ila orta derecede kronik ağrının tedavisinde, özellikle enflamatuar bir bileşeni olan durumlarda etkilidir. Bununla birlikte, yan etkiler yaşlı bir yetişkine reçete edilmeden önce düşünülmelidir. NSAID'ler, önemli morbidite ve mortaliteden sorumlu olan bulantı, ishal ve mukozal hasar (GIS erozyonları, ülserler, perforasyonlar, kanama) dahil olmak üzere bir dizi GIS toksisitesine neden olabilir. Hastaların yüzde otuzunu NSAID tedavisi ile ilgili dispepsi şikayet edecek ve NSAID kullanıcılarının \% 15 ila \% 30'u mide veya duodenum ülseri kanıtı gösterecektir ${ }^{17}$. NSAID'ler, bu ajanları alan hastaların \% 5'inde ortaya çıkan renal toksisite ile de ilişkilidir. Yaşlı yetişkinler, genç hastalardan daha fazla böbrek toksisitesi riski altında olabilir. Hem seçici olmayan hem de seçici COX-2 inhibitörlerinin böbrek fonksiyon bozukluğuna neden olduğu gösterilmiştir, Kreatinin klerensi $30 \mathrm{~mL} / \mathrm{dk}$ 'dan az olan hastalarda NSAID'lerden kaçınılması önerilir. NSAID ayrıca kardiyovasküler risklerle de ilişkilidir. Çalışmalar, hem seçici hem de seçici olmayan NSAID'lerin kalp yetmezliği riskini arttırdığını ve kalp yetmezliği semptomlarını şiddetlendirdiğini göstermiştir. Ayrıca COX-2 seçici NSAID'lerinin büyük vasküler olaylar riski taşıyan hastalarda protrombotik aktiviteye sahip olabileceğine dair kanıtlar vardır. Bu nedenle, yaşlı bir hastanın kardiyak komorbiditeleri NSAID'ler başlamadan önce dikkatle düşünülmelidiriri-22.

Antidepresan İlaçların Akılcı Kullanımı: Trisiklik antidepresanların (TSA), SSRI'lerin ve SNRI'ların yaşlı erişkinlerde artan yan etkileri olduğu bilinmektedir. TSA'lar oldukça antikolinerjiktir ve bilişsel disfonksiyon, sedasyon ve ortostatik hipotansiyona yol açabilir. Tüm TSA'lar, düşük doz doksepin hariç olmak üzere, yaşlı erişkinlerde potansiyel olarak uygun olmayan ilaçlar olarak Beer listesine dahil edilmiştir²3.

Antikonvülzan İlaçların Akılcı Kullanım: Yaşlı yetişkinlerde karbamazepin gibi daha eski antikonvülsanlardan kaçınılmalıdır çünkü hiponatremi riskini arttırırlar. Belirtilen ilk basamak tedavi olduğu durumlarda insidansı azaltmak için en düşük etkili doz kullanılması yan etkileri önleyebilir. Gabapentinoidler yaşlı erişkinlerde başlatıldığında, düşük bir dozda başlatılmalıdır (standart 3-3 günde bir dozlamaya tolere edildiği gibi her 3-4 günde bir $100 \mathrm{mg}$ ile yatmadan önce $100 \mathrm{mg}$ öneririz) ve yan etkiler dikkatle 
izlenmelidir. Gabapentinoidlerin en yaygın yan etkileri baş dönmesi, uyku hali, yorgunluk ve kilo değişiklikleridir24. Bununla birlikte, gabapentinoidlerin reçete oranlarının özellikle son yıllarda üç kata yakın arttığını belirtmekle birlikte bu ilaçların solunum depresyonu üzerinde ek etkilere sahip olabileceğini gösterdiğinden, 65 yaşından büyük yetişkinlerin ve çoklu komorbiditesi olanların kullanımında temkinli olması gerektiği ve zorunlu olmadığı durumlarda tercih edilmemesi önerilir²5.

\section{Sonuç ve Öneriler}

Yaşlı sağlığı hizmeti veren tüm birimlerde özellikle de birinci basamak sağlık hizmetinin sunulduğu aile sağlığı merkezlerinde aile hekimleri tarafından hastaların tedavi planları incelenerek; polifarmasi ve akılcı ilaç kullanımının ilkeleri önemsenmelidir. Bu yaklaşım akut ve kronik hastalıkların tedavi ve kontrolünde, hastanın morbidite ve mortalitesinde, yaşam kalitesinde ve tedavi maliyetinde etkin rol oynayacaktır. Aile hekimleri hastanın tedavisini düzenlerken; alacağı ilaç sayısının mümkün olduğunca sınırlandırılması, ilaç dozunun bireysel özellikleri de göz önünde bulundurularak yaşlının özelliklerine göre planlanması, tedavinin yapısına uygun olarak mümkünse düşük dozla başlanarak kademeli artışın sağlanması, tedaviye yeni başlanacak hastalarda gerekli geriatrik değerlendirmenin tam yapılması, devam edilen tedavilerde ilacın erken dönem ve geç dönem yan etkileri ve komplikasyonları dikkatle değerlendirilerek bireye ya da bakım veren kişiye gerekli bilgilendirmelerin yapılması önemlidir.

Ayrıca hasta her muayeneye geldiğinde, reçetesiz ilaçlar da dâhil kullandığı tüm ilaç ve takviye ürünlerin sorulması ve görülmesi, yazılacak ilaçların klinik endikasyonundan emin olunması da diğer önemli konulardır. İlaçların sıvı formülasyonları veya olanak varsa günde tek uygulamalı olanların tercih edilmeleri, sedasyon yapan, sakinleştirici özelliği olan ilaçların kişinin günlük yaşamındaki faaliyetlerini etkileyebileceğinden dolayı dikkatle önerilmesi ve tüm bu etkileşimlerin sağlanabilmesi için hekim ile hasta ve/veya bakımveren arasında iyi bir iletişimin sağlanması önemlidir. Aile hekimliği sistemi kapsamında hekimin kendisine kayıtlı bir nüfusa hizmet vermesi dolayısıyla başvuran tüm hastaların bireysel, sosyodemografik, tıbbi bilgi ve öykülerine sahip olması hastaya sunacağı koruyucu, tedavi edici ve rehabilitasyon olmak üzere tüm hizmetlerde önemlidir. Bu durum yaşlı bireyin alacağı her türlü tedavi ve tedavi amacıyla düzenleyeceği reçetelerin etkin olması ve hastaya maksimum yararı sağlaması 
konusunda önemli bir ayrıcalıktır. Akılcı ilaç kullanımının bu sistem içinde çok daha rahat uygulanabileceği düşünülmektedir.

\section{KAYNAKLAR}

1. Navaratnarajah A, Jackson SHD. Thephysiology of ageing. Medicine. 2017;45:610

2. Mortazavi SS, Shati M, Keshtkar A, Malakouti SK, Bazargan M, Assari S. Defining polypharmacy in the elderly: a systematic review protocol. BMJ Open. 2016;6:e010989.

3. Duerden M, Avery T, Payne R. Polypharmacy and Medicines Optimisation: Making it Safe and Sound. first ed.,The King's Fund, UK 2013.

4. Secoli SR. Polypharmacy: interaction and adversere actions in the use of drugs by elderly people. RevBrasEnferm. 2010;63:136-40.

5. Kaboli PJ, McClimon BJ, Hoth AB, Barnett MJ. Assessing the accuracy of computerized medication histories. Am J Manag Care. 2004;10:872-877.

6. Gelal A. Yaşlılarda ilaç kullanımını etkileyen farmakodinamik değişiklikler. Türk Geriatri Dergisi. 2006;özel sayı:33-36.

7. Bahat G, Akpınar TS, Tufan F, et al. Yaşlılarda akılcı ilaç kullanımı. J. Gerontol Geriatrik Arş. 2012:1(1):104-109.

8. Akan P, Erdinçler D, Tezcan V, Beğer T. Yaşlıda ilaç kullanımı. Türk Geriatri Dergisi 1999;2:33-8.

9. Karadakovan A. Yaşlı Sağh̆̆̆ ve Bakım. Ankara: Özyurt Basımevi, 2014

10. Işık AT, Doruk H, Mas MR. Yaşlılarda ilaç kullanım ilkeleri. Klinik Gelişim Dergisi. 2004;17(2):25-31.

11. Doshi JA, Shaffer T, Briesacher BA. National estimates of medication use in nursing homes: findings from the 1997 medicare current beneficiary survey and the 1996 medical expenditure survey. J Am GeriatrSoc. 2005;53:438-443. 
12. Arslan Ş, Atalay A, Gökçe-Kutsal Y. Yaşlılarda ilaç tüketimi. Türk Geriatri Dergisi. 2007;3(2):56-60.

13. İskit BA. Akılcı ilaç kullanımı. Sürekli Tıp Eğitimi Dergisi. 2006;15(7):4-5.

14. Yeşil Y, Cankurtaran M, Kuyumcu ME. Polifarmasi. Klinik Gelişim Dergisi. 2012;25(3):18-23.

15. Azad N, Tierney M, Victor G, et al. Adverse drug events in the elderly population admitted to a tertiary care hospital. J HealthcManag. 2002;47:295-306.

16. Schwan J, Sclafani J, Tawfik VL. Chronic Pain Management in the Elderly. Anesthesiology Clinics. 2019;37(3):547-560. doi:10.1016/j.anclin.2019.04.012

17. Hawkey CJ. Nonsteroidal anti-inflammatory drug gastropathy. Gastroenterology. 2000;119(2):521-35.

18. Shimp LA. Safety issues in the pharmacologic management of chronic pain in the elderly. Pharmacotherapy. 1998;18(6):1313-22.

19. Morales E, Mucksavage JJ. Cyclooxygenase-2 inhibitor-associated acute renal failure: case report with rofecoxib and review of the literature. Pharmacotherapy. 2002;22(10):1317-21.

20. Gloth FM. Pharmacological management of persistent pain in older persons: focus on opioids and nonopioids. J Pain. 2011;12(3 Suppl 1):S14-20.

21. Schmidt M, Lamberts M, Olsen A-MS, et al. Cardiovascular safety of nonaspirin non-steroidal anti-inflammatory drugs: review and position paper by the working group for Cardiovascular Pharmacotherapy of the European Society of Cardiology. Eur Heart J. 2016;37(13):1015-23.

22. Coxib and traditional NSAID Trialists' (CNT) Collaboration, Bhala N, Emberson J, Merhi A, et al. Vascular and upper gastrointestinal effects of non-steroidal anti-inflammatory drugs: meta-analyses of individual participant data from randomised trials. Lancet. 2013;382(9894):769-79.

23. Coupland CA, Dhiman P, Barton G, et al. A study of the safety and harms of antidepressant drugs for older people: a cohort study using a large primary care database. Health Technol Assess. 2011;15(28):1-202, iii-iv. 
24. Straube S, Derry S, Moore RA, et al. Pregabalin in fibromyalgia: meta-analysis of efficacy and safety from company clinical trial reports. Rheumatology (Oxford). 2010;49(4):706-15.

25. Johansen ME. Gabapentinoid use in the United States 2002 through 2015. JAMA Intern Med. 2018;178(2):292-4. 